\title{
Light Scattering and Viscometric Study of Cellulose in Aqueous Lithium Hydroxide
}

\author{
Kenji KAMIDE and Masatoshi SAITo \\ Fundamental Research Laboratory of Fibers and Fiber-Forming Polymers, \\ Asahi Chemical Industry Co., Ltd., \\ Takatsuki, Osaka 569, Japan \\ (Received February 6, 1986)
}

\begin{abstract}
An attempt was made to determine molecular parameters of cellulose dissolved in simple solvents. Cellulose regenerated from a cuprammonium solution of acid-hydrolized cotton linters was found to dissolve molecularly, without suffering molecular degradation, into $6 \mathrm{wt} \%$ aqueous $\mathrm{LiOH}$ solution by choosing an adequate condition. The apparent weight-average molecular weight $M_{w}^{*}$, of cellulose obtained by light scattering in a non-dialyzed aqueous $\mathrm{LiOH}$, was converted into the correct weight-average molecular weight $M_{w}$ with the aid of the data on $M_{w}^{*}$ and $M_{w}$ for a dialyzed cadoxen solution of cellulose. The Mark-Houwink-Sakurada equation for cellulose in aq $\mathrm{LiOH}$ was $[\eta]=2.78 \times 10^{-2} \mathrm{M}_{w}^{0.79}$ at $25^{\circ} \mathrm{C}\{[\eta]$; limiting viscosity number $\}$. The Flory's viscosity parameter $\Phi$ for this system was significantly smaller than the theoretical value for unperturbed chains at non-draining limit, showing a molecular weight dependence. The linear expansion factor for the radius of gyration was always below 1.04 as estimated from the penetration function. The unperturbed chain dimensions were estimated by various methods using the light scattering and/or viscometric data. Cellulose was found to be semiflexible in aq $\mathrm{LiOH}$.

KEY WORDS Cellulose / Aqueous Alkali Solution / Light Scattering /

Viscosity / Draining Effect / Excluded Volume Effect / Unperturbed Chain

Dimension /
\end{abstract}

Cellulose is a linear macromolecule composed of anhydroglucose residue units linked at 1 and 4 positions through glucosidic bonds with the beta configuration. Cellulose has been widely utilized as starting materials of papers, fibers, plastics and membranes. The importance of cellulose materials is increasing, particularly after oil-shortage, because it is absolutely reproducible. Unfortunately, the reliable knowledge on cellulose molecular characteristics is extremely poor due to the wellknown fact that stable and "simple" solvent, in which cellulose can be dissolved molecularly, has not been found hitherto: Molecular decomposition cannot be avoided if strong acids or alkalis were used. Most of metal complex alkali solutions decompose cellulose by oxidation, and they are unstable and coloured. In addition, cellulose dissolves with formation of complex into these solutions. Hydrazine and $N$-morphorin- $N$-oxide can also dissolve cellulose, but these are sometimes explosive and highly toxic. Therefore, the above solvents could not be used for molecular characterization of cellulose. Recently, Terbojevich et al. ${ }^{1}$ performed light scattering measurements on dilute and concentrated solutions of cellulose in $N, N$-dimethylacetamide (DMAc)/ $\mathrm{LiCl}$ mixture, but they did not carry out detailed survey of molecular characteristics due to gel contamination in the solutions.

Kamide et $a l^{2}$ found that regenerated cellulose having relatively large molecular weight dissolved without forming alcoholate in aqueous $\mathrm{NaOH}$ solution at $4^{\circ} \mathrm{C}$ and the solubility in 
the solvent was closely correlated with the relative amount of the local region where intramolecular hydrogen bonds are at least partly broken.

In this article, we intend to show that cellulose can be dissolved in a $6 \mathrm{wt} \% \mathrm{LiOH}$ aq solution without showing significant decomposition and that the molecular characteristics of cellulose can be determined in the aqueous LiOH solution by light scattering and viscosity measurements.

\section{EXPERIMENTAL}

\section{Cellulose Samples}

Regenerated cellulose samples having different molecular weights can be obtained from a cuprammonium solution $\left(\mathrm{Cu}, 11 ; \mathrm{NH}_{3}, 200\right.$; water, 1000; gram unit) of cellulose by altering the storage time of the solution at dark place in air. The viscosity $\eta$ of the solution decreases gradually during storage due to acid hydrolysis as shown in Figure 1. Here $\eta$ was measured at $25^{\circ} \mathrm{C}$ with a cone-and-plate type viscometer Rotovisco ${ }^{\circledR}$ (Haake, FRG) at angular velocity of 1.26 and $3.14 \mathrm{rad} \mathrm{s}^{-1}$. Thus, by adding $5 \mathrm{wt} \%$ aq $\mathrm{H}_{2} \mathrm{SO}_{4}$ to six cuprammonium solutions with different storage times, six regenerated cellulose samples, SA-1 -6 , were prepared as precipitates, and they were washed with acetone, and dried in vacuo.

\section{Preparation of Cellulose-aq LiOH Solution}

In order to determine the optimum range of $\mathrm{LiOH}$ concentration $\phi_{\mathrm{L}}(\mathrm{wt} \%)$ for dissolving cellulose II solid in aq $\mathrm{LiOH}$, the solubility of cellulose was investigated in the range of $\phi_{\mathrm{L}}$ from 3 to $10 \mathrm{wt} \%$. For this purpose, aq $\mathrm{LiOH}$ solution was prepared in the following manner: $\mathrm{LiOH}$ (purity $98.0 \%$ ) anhydride (manufactured by Kishida Chemicals Co., Osaka) was dissolved at $10^{\circ} \mathrm{C}$ in distilled water of liquid chromatogram grade (made by Wako Junyaku Co., Osaka) with agitation. The solution was boiled at room temperature under the reduced atmosphere $(c a .1 .3 \mathrm{~Pa})$ to

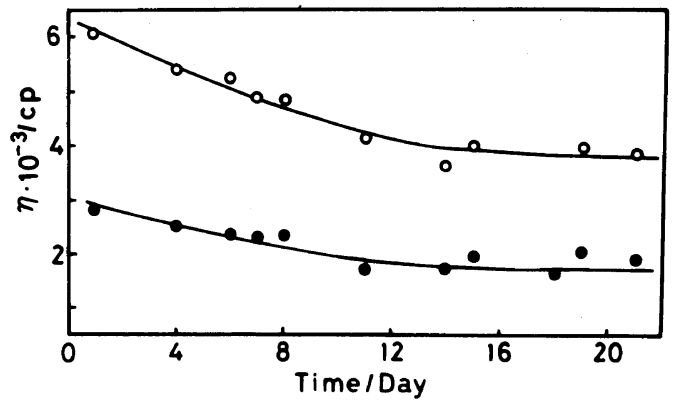

Figure 1. Change in the viscosity $\eta$ of cellulosecuprammonium solution (cellulose concentration, $6 \mathrm{wt} \%$ ) at $25^{\circ} \mathrm{C}$ during the storage. Angular velocity, 1.26 $\mathrm{rad} \mathrm{s}^{-1}(\mathrm{O})$ and $3.14 \mathrm{rad} \mathrm{s}^{-1}(\mathrm{O})$.

Table I. Dependence of solubility of cellulose ( $1 \mathrm{wt} \%$ to aq $\mathrm{LiOH}$ solution) on the concentration of lithium hydroxide $(w t \%)$ in water at $25^{\circ} \mathrm{C}^{\mathrm{a}}$

\begin{tabular}{llllllcl}
$\begin{array}{c}\text { Concentration of } \\
\mathrm{LiOH} / \mathrm{wt} \%\end{array}$ & 3 & 4 & 5 & 6 & 8 & 10 \\
\hline $\begin{array}{c}\text { Solubility of } \\
\text { cellulose }\end{array}$ & $\times$ & $\triangle$ & $\triangle-\bigcirc$ & $\bigcirc$ & $\triangle-\bigcirc$ & $\times$
\end{tabular}

a $\bigcirc$, soluble; $\triangle$, only swell; $\times$, insoluble.

exclude the dissolved gas. Dried regenerated cellulose flakes (sample code SA-1) were dipped in aq $\mathrm{LiOH}$, thus prepared, at $4^{\circ} \mathrm{C}$ for $24 \mathrm{~h}$ to give a $1 \mathrm{wt}^{\mathrm{o}} \%$ cellulose slurry. The slurry was agitated for $1 \mathrm{~min}$ by a home mixer followed by quenching at $-70^{\circ} \mathrm{C}$ in liquid nitrogen, stored for $1 \mathrm{~h}$ at $-70^{\circ} \mathrm{C}$, and heated gradually up to the room temperature. Table I shows the experimental relations between the solubility behavior of cellulose II in aq $\mathrm{LiOH}$ and $\phi_{\mathrm{L}}$ at room temperature. Obviously, cellulose II is insoluble in aq $\mathrm{LiOH}$ with $\phi_{\mathrm{L}}$ less than $3 \mathrm{wt} \%$ or larger than $10 \mathrm{wt} \%$, and is dissolved or swollen in aq $\mathrm{LiOH}$ with $\phi_{\mathrm{L}}$ ranging $5-8 \mathrm{wt} \%$. At $\phi_{\mathrm{L}}=6 \mathrm{wt} \%$, cellulose gave a transparent and clean solution. On the basis of the above preliminary experimental result, the aq $\mathrm{LiOH}$ solution with $\phi_{\mathrm{L}}=6 \mathrm{wt} \%$ was chosen as a solvent for the light scattering and viscosity measurements. A series of 0.6 $\mathrm{wt} \%$-solutions of cellulose in aq $\mathrm{LiOH}\left(\phi_{\mathrm{L}}=\right.$ 
$6 \mathrm{wt}^{\mathrm{o}} \%$ ) were prepared by the procedure described before.

\section{Solution Viscosity}

Aqueous $\mathrm{LiOH}$ and cadoxen were used as solvents for the viscosity measurements. Here cadoxen is a mixture of cadmiumethylenediamine-water- $\mathrm{NaOH}(5: 28: 166: 14$, weight ratio) which is the same composition as used by Henley, ${ }^{3}$ and Brown and Wirkström. ${ }^{4}$ The solution viscosity of SA-1-6, was measured by using a modified Ubbelohde suspension type viscometer at $25^{\circ} \mathrm{C}$. On sample code SA-3, the measurement was also performed at other temperatures in the range -5.0 to $45.0^{\circ} \mathrm{C}$. The limiting viscosity number $[\eta]$ was determined by the Huggins plot $\{$ i.e., $\eta_{\mathrm{sp}} / c\left(\eta_{\mathrm{sp}}\right.$, specific viscosity; $c$, polymer weight concentration) vs. $c$ plot $\}$.

\section{Light Scattering}

A preliminary attempt to estimate the specific refractive index increment under constant chemical potential of $\mathrm{LiOH},(\partial n / \partial c)_{\mu}$, was unfortunately ended in failure, because of nonavailability of a suitable membrane, not swollen in $6 \mathrm{wt} \%$ aq $\mathrm{LiOH}$. Then, as a next best method, $(\partial n / \partial c)$ at constant $\mathrm{LiOH}$ fraction in aq $\mathrm{LiOH}$, designated as $(\partial n / \partial c)_{\phi_{\mathrm{L}}}$, was determined in a conventional manner. Using this value, the light scattering data analyzed to give the apparent weight-average molecular weight $M_{w}^{*}$, apparent secondvirial coefficient $A_{2}^{*}$, and $z$-average radius of gyration $\left\langle S^{2}\right\rangle_{z}^{1 / 2}$. In order to evaluate the absolute molecular weight of cellulose samples, cellulose (sample code SA-1 and SA-5) solutions in cadoxen were dialyzed using a commercially available cellulose tube from Union Carbide Co. (U.S.A.) in an apparatus specially designed and constructed by us. The attainment of Donnan membrane equilibrium after 5 days dialysis was confirmed by measuring the electrical conductivity of the solution. $(\partial n / \partial c)_{\mu}$ of cellulose-cadoxen and $(\partial n / \partial c)_{\phi_{\mathrm{L}}}$ of cellulose-aq $\mathrm{LiOH}$ were de- termined by a Shimadzu differential refractometer type DR-4 at $25^{\circ} \mathrm{C}$ with the incident light of wave length $\lambda_{\mathrm{o}}$ of $436 \mathrm{~nm}$.

The light scattering experiments were carried out for cellulose-cadoxen and cellulose-aq $\mathrm{LiOH}$ in the following manner: The solution was centrifuged by a Hitachi model $55 \mathrm{p}-7$ automatic preparative centrifuge at $1 \times 10^{5}$ gravity for $1 \mathrm{~h}$ and then filtered through a poly(tetrafluoroethylene) membrane filter FP series (pore diameter 0.1, 0.22, 0.3 , and $0.45 \mu \mathrm{m})$, manufactured by Sumitomo Denko Co. (Osaka). In this case, the membrane with larger pore diameter was used for more concentrated solutions. The intensity of scattered light was measured at $25^{\circ} \mathrm{C}$ by a FICA photogonio diffusiometer, 42000 with unpolarized incident light of $\lambda_{\mathrm{o}}=436 \mathrm{~nm}$. Using the ratio of $M_{w}^{*}$ in nondialyzed aq $\mathrm{LiOH}$ to $M_{w}$ in dialyzed cadoxen for the samples SA-1 and 5, $M_{w}^{*}$ of other samples was converted to $M_{w}$ by the linear interpolation method.

\section{RESULTS AND DISCUSSION}

Figure 2 shows the plots of $\eta_{\mathrm{sp}} / c$ against $c$ for cellulose in a $\mathrm{LiOH}$ and in cadoxen at $25^{\circ} \mathrm{C}$. For cellulose samples with larger molecular weight the plots became non-linear at larger $c$ region: [ $\eta$ ] and the Huggins coefficient $k^{\prime}$ were estimated from the intercept and initial slope of the plots as summarized in Table II. $[\eta]$ in aq $\mathrm{LiOH}$ is, except sample SA6 , almost the same or very slightly ( $c a .1 \%$ ) larger than that in cadoxen, but $k^{\prime}$ in the former is some 1.7 times larger than that in the later.

Figure 3 shows the temperature dependence of $[\eta]$ of sample SA-3 in aq $\mathrm{LiOH}\left(\phi_{\mathrm{L}}=6 \mathrm{wt} \%\right)$ and the figure also includes the literature data (sample code P1, P2, and P3) by Henley ${ }^{3}$ on cellulose in cadoxen. [ $\eta$ ] for cellulose-aq LiOH system decreases monotonically with increasing temperature in a similar way as $[\eta]$ for cellulose in cadoxen does. It has been noted 


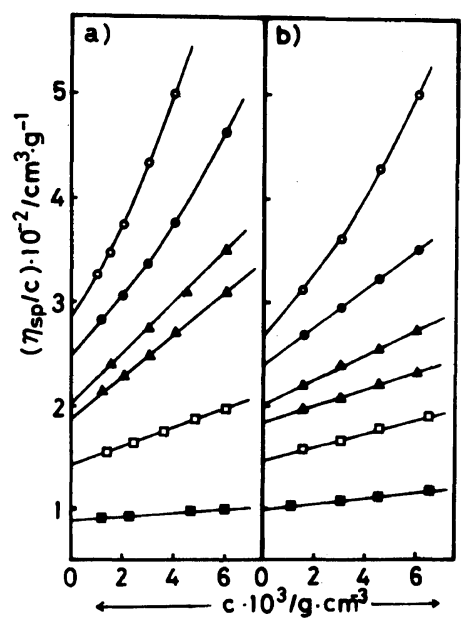

Figure 2. Plots of the ratio of specific viscosity $\eta_{\mathrm{sp}}$ to polymer concentration $c, \eta_{\mathrm{sp}} / c$ against $c$ for cellulose in $6 \mathrm{wt} \%$ aq $\mathrm{LiOH}$ solution (a) and in cadoxen (b) at $25^{\circ} \mathrm{C}$. O, SA-1; , SA-2; $\triangle$, SA-3; $\triangle$, SA-4; $\square$, SA-5;, , SA6.

Table II. Limiting viscosity number $[\eta]$ and Huggins constant $k^{\prime}$ of regenerated cellulose in $6 \mathrm{wt} \%$ aq $\mathrm{LiOH}$ and in cadoxen at $25^{\circ} \mathrm{C}$

\begin{tabular}{cccccc}
\hline \multirow{2}{*}{$\begin{array}{c}\text { Sample } \\
\text { code }\end{array}$} & \multicolumn{2}{c}{$6 \mathrm{wt} \% \mathrm{LiOH}$} & & \multicolumn{2}{c}{ Cadoxen } \\
\cline { 2 - 3 } \cline { 5 - 6 } \cline { 5 - 6 } & {$[\eta] 10^{-2 \mathrm{a}}$} & $k^{\prime}$ & & {$[\eta] 10^{-2 \mathrm{a}}$} & $k^{\prime}$ \\
\hline SA-1 & 285 & 0.58 & & 270 & 0.43 \\
SA-2 & 248 & 0.51 & & 241 & 0.32 \\
SA-3 & 204 & 0.57 & & 201 & 0.30 \\
SA-4 & 187 & 0.70 & & 185 & 0.23 \\
SA-5 & 141 & 0.51 & & 146 & 0.32 \\
SA-6 & 89 & 0.36 & & 99 & 0.27 \\
\hline
\end{tabular}

a $\mathrm{cm}^{3} \mathrm{~g}^{-1}$.

that $[\eta]$ of cellulose derivative solutions shows a negative temperature dependence. ${ }^{5}$ Suzuki et $a l .{ }^{5}$ measured the viscosity and the light scattering for cellulose diacetate (CDA)-acetone system at temperature ranging $12-50^{\circ} \mathrm{C}$ and concluded that the negative temperature dependence of $[\eta]$ of CDA solution is mainly attributable to a negative temperature coefficient of the unperturbed chain dimension $A$ and that the temperature dependences of the excluded volume effect and the hydrodynamic interaction are rather minor factors. There-

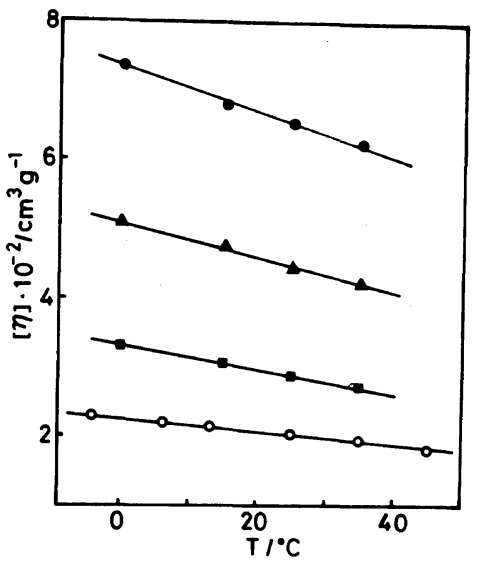

Figure 3. Temperature $(T)$ dependence of the limiting viscosity number. $[\eta]$ of cellulose-solvent systems. Open mark, cellulose (sample code SA-3)-aq LiOH (this work) and closed mark, cellulose-cadoxen system. ${ }^{3}$, sample code $\mathrm{P} 1 ; \boldsymbol{\Delta}, \mathrm{P} 2 ; \mathbf{\square}, \mathrm{P}$.

after, we evaluated the number of solvent molecules, $s_{0}$, solvated to a pyranose ring at infinite dilution from the adiabatic compressibility of CDA-acetone system. ${ }^{6}$ The value of $s_{\mathrm{o}}$ decreases monotonically with increasing temperature from 10 to $50^{\circ} \mathrm{C}$ in the similar manner as $A$ does. ${ }^{6}$ This result for the CDA solution may be explained from the possibility that the increased difficulty in occurrence of solvation induces a significant increase in flexibility of the unperturbed chains. The same explanation may also be applied to the negative temperature dependence of $[\eta]$ of cellulose-solvent systems.

$(\partial n / \partial c)_{\mu}$ for sample SA-1 and 5 in cadoxen were found to be 0.194 and $0.198 \mathrm{~cm}^{3} \mathrm{~g}^{-1}$, respectively. These values are larger than those by Vink and Dahlström $(0.193)^{7}$ and Henley $(0.183-0.193)^{3} \quad(\partial n / \partial c)_{\phi_{\mathrm{L}}}$ for sample SA$1 \sim \mathrm{SA}-6$ in aq $\mathrm{LiOH}$ was $0.134 \pm 0.04 \mathrm{~cm}^{3} \mathrm{~g}^{-1}$.

Figure 4 shows typical Zimm plots of cellulose (here, sample SA-5) in cadoxen (a) and in aq $\mathrm{LiOH}$ (b). In these solvents Zimm's plots did not display any significant distortion. Table III summarizes $M_{w}, A_{2},\left\langle S^{2}\right\rangle_{z}^{1 / 2}$ of sample SA-1 and SA-5 in cadoxen and $M_{w}^{*}$ of the samples in aq LiOH. $M_{w}^{*}$ of SA-1 and SA- 
Table III. Light scattering data of sample code SA-1 and SA-5 in cadoxen and in $6 \mathrm{wt} \%$ aq LiOH and the viscosity-average molecular weight $M_{v}$ determined using Mark-Houwink-Sakurada equation in cadoxen established by Henley et al. ${ }^{3,4}$ at $25^{\circ} \mathrm{C}$

\begin{tabular}{|c|c|c|c|c|c|}
\hline \multirow{3}{*}{ Sample code } & \multicolumn{4}{|c|}{ Light scattering } & \multirow{3}{*}{$\begin{array}{l}\text { Viscosity } \\
\text { Cardoxen } \\
M_{v} \times 10^{-4}\end{array}$} \\
\hline & \multicolumn{3}{|c|}{ Cadoxen (dialyzed) } & \multirow{2}{*}{$\frac{6 \mathrm{wt} \% \text { aq LiOH }}{M_{w}^{*} \times 10^{-4 \mathrm{c}}}$} & \\
\hline & $M_{w} \times 10^{-4}$ & $\left\langle S^{2}\right\rangle_{z}^{1 / 2} \times 10^{6 \mathrm{a}}$ & $A_{2} \times 10^{3 \mathrm{~b}}$ & & \\
\hline SA-1 & 12.0 & 3.51 & 2.29 & 19.1 & 11.5 \\
\hline SA-5 & $5.2_{6}$ & 2.29 & 2.95 & 7.6 & $5.1_{2}$ \\
\hline
\end{tabular}

a $\mathrm{cm}$.

b $\mathrm{cm}^{3} \mathrm{~g}^{-1}$.

c The apparent weight-average molecular weight determined for non-dialyzed $6 \mathrm{wt} \%$ aq $\mathrm{LiOH}$ solution.

d Calculated using MHS equation (eq 2) established by Brown and Wirkström. ${ }^{4}$

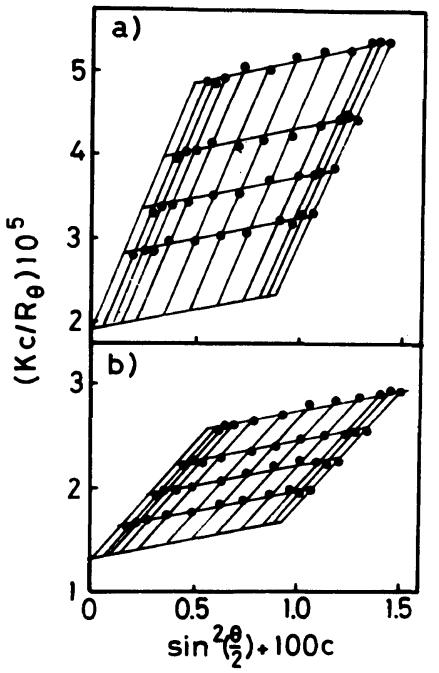

Figure 4. Typical Zimm plots of cellulose (sample code SA-5) in cadoxen (a) and in aq $\mathrm{LiOH} \mathrm{(b).}$

5 is some $60 \%$ and $40 \%$ larger than $M_{w}$ in dialyzed cadoxen solutions of SA-1 and SA-5, respectively.

A parameter representing selective adsorption, $\alpha_{\mathrm{a}}$, is related to $M_{w}$ and $M_{w}^{*}$ through the relation $^{8}$

$$
\alpha_{\mathrm{a}}=\left\{\left(M_{w}^{*} / M_{w}\right)^{1 / 2}-1\right\}(\partial n / \partial c)_{\phi_{\mathrm{L}}} /\left(\partial n_{\mathrm{o}} / \partial \phi_{\mathrm{L}}\right)
$$

where $\partial n_{\mathrm{o}} / \partial \phi_{\mathrm{L}}$ is an increment of refractive index of aq $\mathrm{LiOH}$ and was $0.31 \mathrm{~cm}^{3} \mathrm{~g}^{-1}$ near 6 $\mathrm{wt}^{\mathrm{o}} \% \mathrm{LiOH}$ concentration. From eq 1 , the $\alpha_{\mathrm{a}}$ for SA-1 and 5 in aq $\mathrm{LiOH}$ was determined as $0.11_{7}$ and 0.088 , respectively. These comparatively large $\alpha_{\mathrm{a}}$ values suggest strongly the possibility of preferential adsorption of lithium cation or the hydroxyl group of $\mathrm{LiOH}$ on cellulose, rather than water molecules.

Brown and Wirkström ${ }^{4}$ obtained the parameter $K_{\mathrm{m}}$ and $a$ in the Mark-HouwinkSakurada (MHS) relation

$$
[\eta]=K_{\mathrm{m}} M^{a}
$$

for cellulose in cadoxen, analyzing their own and Henley's ${ }^{3}$ data, to be $3.85 \times 10^{-2} \mathrm{~cm}^{3} \mathrm{~g}^{-1}$ and 0.76 , respectively. Using their relation we estimated the viscosity-average molecular weight $M_{v}$ of sample SA-1 and 5 from $[\eta]$ in cadoxen as compiled in the 6th column of Table III. $M_{v}$ of two samples thus estimated was in good agreement with $M_{w}$ directly determined in our laboratory by the light scattering method in cadoxen within an experimental uncertainty. Henley ${ }^{3}$ observed that two cellulose samples $\left(M_{w}=2.9 \times 10^{5}\right.$ and $2.25 \times 10^{5}$ ), both prepared by hydrolysis of cotton linter $\left(M_{w}=9.45 \times 10^{5}\right)$ with $2 N \mathrm{HCl}$, had $M_{w} / M_{n}\left(M_{n}\right.$, the number-average molecular weight) of approximately 2. Brown and Wirkström ${ }^{4}$ reported that $M_{w} / M_{n}$ of acid (2-2.5 $\mathrm{N} \mathrm{H}_{2} \mathrm{SO}_{4}$ )-hydrolyzed cotton linters having $M_{w}$ of $3.36 \times 10^{4}$ to $1.65 \times 10^{4}$ was on 
Table IV. Results of light scattering measurements at $25^{\circ} \mathrm{C}$ and various parameters of cellulose- $\mathrm{LiOH} 6 \mathrm{wt} \%$ aq solution system

\begin{tabular}{|c|c|c|c|c|c|c|c|c|}
\hline \multirow{3}{*}{$\begin{array}{c}\text { Sample } \\
\text { code }\end{array}$} & \multicolumn{6}{|c|}{ Light scattering } & \multirow{3}{*}{$\Phi \times 10^{-22}$} & \multirow{3}{*}{$\alpha_{s}^{d}$} \\
\hline & \multirow{2}{*}{$M_{w}^{*} \times 10^{-4}$} & \multirow{2}{*}{$\frac{\left\langle S^{2}\right\rangle_{z}^{1 / 2} \times 10^{6}}{\mathrm{~cm}}$} & \multirow{2}{*}{$\frac{A_{2}^{*} \times 10^{3}}{\mathrm{~cm}^{3} \mathrm{~g}^{-1}}$} & \multirow{2}{*}{$M_{w} \times 10^{-4}$} & \multirow{2}{*}{$\frac{A_{2} \times 10^{3 \mathrm{~b}}}{\mathrm{~cm}^{3} \mathrm{~g}^{-1}}$} & \multirow{2}{*}{$M_{v} \times 10^{-4 \mathrm{c}}$} & & \\
\hline & & & & & & & & \\
\hline SA-1 & 19.1 & 3.94 & 1.09 & 12.0 & 1.73 & 11.5 & $7.6_{9}$ & 1.04 \\
\hline SA-2 & 15.1 & 3.61 & 1.11 & $(9.6)^{\mathrm{a}}$ & 1.74 & 9.9 & $6.9_{6}$ & 1.03 \\
\hline SA-3 & 12.1 & 3.25 & 1.10 & $(8.0)^{\mathrm{a}}$ & 1.67 & 7.8 & $6.5_{3}$ & 1.03 \\
\hline SA-4 & 11.5 & 2.97 & 1.22 & $(7.6)^{a}$ & 1.84 & 7.0 & $7.4_{6}$ & 1.04 \\
\hline SA-5 & 7.6 & 2.46 & 1.12 & $5.2_{6}$ & 1.62 & 5.1 & $6.8_{5}$ & 1.03 \\
\hline SA-6 & 3.8 & 1.94 & 1.41 & $(2.8)^{\mathrm{a}}$ & 1.94 & 3.1 & $4.6_{9}$ & 1.02 \\
\hline
\end{tabular}

a Estimated value.

b Corrected value with use of eq 3 .

c Calculated from $[\eta]$ in cadoxen at $25^{\circ} \mathrm{C}$ using MHS equation by Brown and Wirkström. ${ }^{4}$

d Calculated using eq 7-10.

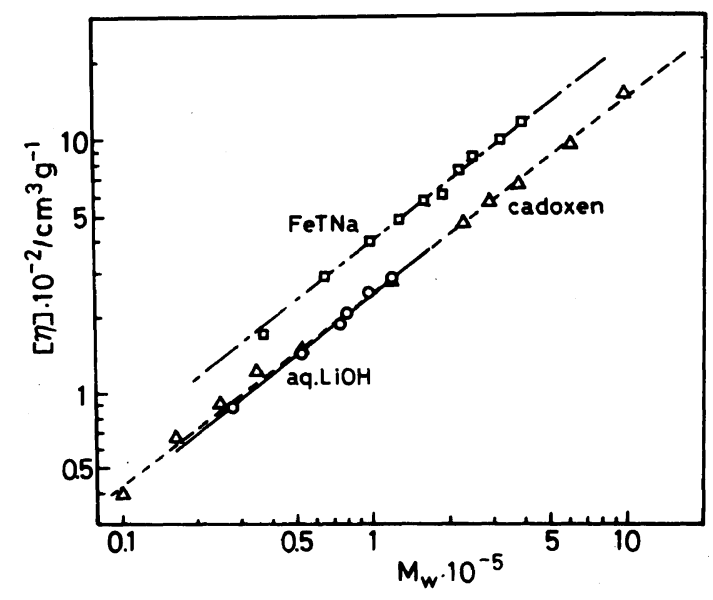

Figure 5. Log-log plots of the limiting viscosity number $[\eta] v s$. the weight-average molecular weight $M_{w}$ of cellulose in $6 \mathrm{wt} \%$ aq $\mathrm{LiOH}$ (circle, this work), cadoxen (triangle) and $\mathrm{FeTNa}$ (rectangle) ${ }^{9}$ at $25^{\circ} \mathrm{C}$. $\mathbf{\Delta}$, this work; $\triangle$..Henley, ${ }^{3}$ Brown and Wirkström. ${ }^{4}$

average about 2. These experimental facts indicate that acid-hydrolysis of cotton linter proceeds according to random scission of the polymer chains and if it proceeds to a greater extent, the products have $M_{w} / M_{n} \cong 2$. Hence, all the samples employed here can be regarded to have the same polymolecularity as those of Henley and Brown-Wirkström.

The second $\sim$ fourth columns of Table IV show the experimental results of $M_{w}^{*},\left\langle S^{2}\right\rangle_{z}^{1 / 2}$,
Table V. Parameters for the Mark-Houwink-Sakurada equation, $[\eta]=K_{\mathrm{m}} M^{a}$, as determined for cellulose in several alkaline solvents

\begin{tabular}{|c|c|c|c|c|}
\hline Solvent & $\frac{K_{\mathrm{m}} \times 10^{2}}{\mathrm{~cm}^{3} \mathrm{~g}^{-1}}$ & $a$ & $\begin{array}{l}\text { Method for } \\
\text { determining } \\
\text { molecular } \\
\text { weight }\end{array}$ & $\begin{array}{c}\text { Refer- } \\
\text { ence }\end{array}$ \\
\hline $6-w t \%$ aq $\mathrm{LiOH}$ & $2.7_{8}$ & 0.79 & $\mathbf{L S}^{\mathbf{a}}$ & This work \\
\hline \multirow[t]{2}{*}{ Cadoxen } & $3.8_{5}$ & 0.76 & LS & 4 \\
\hline & $5.5_{1}$ & 0.75 & $\mathrm{SD}^{\mathrm{b}}$ & 3 \\
\hline $\mathrm{FeTNa}^{\mathrm{c}}$ & $5.3_{1}$ & 0.78 & LS & 7 \\
\hline Cuoxam $^{\mathrm{d}}$ & 0.70 & 0.9 & SD & 3 \\
\hline Cuen ${ }^{e}$ & $1.0_{1}$ & 0.9 & SD & 3 \\
\hline EWNN $^{\mathrm{f}}$ & $0.38_{7}$ & $1.0_{1}$ & SD & 3 \\
\hline
\end{tabular}

a Light scattering.

b Sedimentation-diffusion.

c Iron-Sodium-Tartrate.

d Cupriammonium hydroxide.

e Cupriethylenediamine hydroxide.

f Eisen-Weisäure-Natrium Komplex (iron-tartaric acid-sodium complex solution).

$A_{2}^{*}$ on cellulose-aq $\mathrm{LiOH}$ systems. The fifth column of the table compiles $M_{w}$ which were obtained by the method already explained. $A_{2}$ can be evaluated from $A_{2}^{*}$ by ${ }^{8}$

$$
A_{2}=\left(M_{w}^{*} / M_{w}\right) A_{2}^{*}
$$

as summarized in the sixth column of the table.

Figure 5 shows the plot of $[\eta]$ against $M_{w}$ for 
cellulose in aq $\mathrm{LiOH}$. The figure contains also the literature data on cellulose in cadoxen ${ }^{3,4}$ and in iron-sodium tartrate (FeTNa). ${ }^{9}[\eta]$ in $\mathrm{FeTNa}$ is the largest among those in three solvents.

Table $\mathrm{V}$ lists the parameters $K_{\mathrm{m}}$ and $a$ in eq 2 established using the least-squares method for cellulose-aq $\mathrm{LiOH}$ systems at $25^{\circ} \mathrm{C}$ and the corresponding literature data for other solvents. ${ }^{3,4,9}$ The exponent $a$ for aq $\mathrm{LiOH}$, cadoxen and FeTNa lies between $0.76-0.79$ and $a$ for cupriammonium hydroxide (Cuoxam), cupriethylenediamine hydroxide (Cuen), and EWNN (Eisen-WeinsäureNatrium Komplex, discovered by Jayme and Verburg $^{10}$ ) is larger than 0.9. For the latter solvent groups, the sedimentation-diffusion average molecular weight $M_{\text {SD }}$ were employed in place of $M_{w}$. The MHS equations obtained using $M_{\mathrm{SD}}$ are theoretically expected to be rather sensitive to the polymolecularity of the polymer samples. Then, it should be necessary, in advance to conclude about the flexibility of cellulose in these solvents, to confirm that the samples can be regarded as monomolecular or that the molecular weight dependence of the polymolecularity of the sample is small enough to be neglected. As is well known, $a$ exceeds 0.9 for cellulose nitrate (total degree of substitution $\langle\langle F\rangle, 2.91$ and 2.55)-acetone, cellulose tricarbanilate-acetone and -dioxane systems ${ }^{11}$ : These cellulose derivatives are semiflexible polymers.

Figure 6 shows the molecular weight dependence of $\left\langle S^{2}\right\rangle_{z}^{1 / 2}$ and $A_{2}$ of cellulose in aq $\mathrm{LiOH}$ and cadoxen. The literature data ${ }^{3,4,9}$ for cadoxen and FeTNa are also shown in the figure. Here, it should be noted that Brown and Wirkström ${ }^{4}$ did not determine $\left\langle S^{2}\right\rangle_{z}^{1 / 2}$ because no angular dependence of the reduced scattering intensity was observed within an experimental uncertainty. $\left\langle S^{2}\right\rangle_{z^{\prime}}^{1 / 2}$ of cellulose in aq $\mathrm{LiOH}$ can be expressed as

$$
\left\langle S^{2}\right\rangle_{z}^{1 / 2}=9.1 \times 10^{-9} M_{w}^{0.52} \quad(\mathrm{~cm})
$$

$\left\langle S^{2}\right\rangle_{z}^{1 / 2}$ in cadoxen and FeTNa is proportional

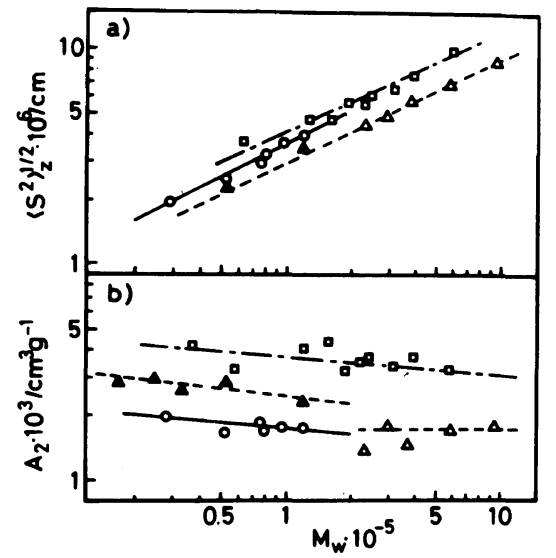

Figure 6. The molecular weight dependence of the $z$ average radius of gyration $\left\langle S^{2}\right\rangle_{z}^{1 / 2}$ and the second virial coefficient $A_{2}$ of cellulose in $6 \mathrm{wt} \%$ aq LiOH (O), cadoxen $\left(\triangle,^{3} \Delta,{ }^{4} \Delta\right.$, this work) and FeTNa ( $\left.\square\right) .^{9}$

to $M_{w}^{0.5}$. Our $\left\langle S^{2}\right\rangle_{z}^{1 / 2}$ data for cadoxen are slightly larger than the values interpolated from the Henley's data. ${ }^{3}$

$A_{2}$ of cellulose in aq $\mathrm{LiOH}$, cadoxen and FeTNa lies roughly between $1.5-5 \times 10^{-3}$ $\mathrm{cm}^{3} \mathrm{~g}^{-1}$. The log-log plots of $A_{2}$ and $M_{w}$ of the data for cellulose-cadoxen system by Brown and Wirkström $\left(M_{w} \leq 4 \times 10^{4}\right)$ and those by Henley $\left(M_{w}>2 \times 10^{5}\right)$ make two different lines. The present data for cellulose-cadoxen system are near the extrapolated line of Brown and Wirkström data. Except for Henley's data for which large experimental error was pointed out by him, $A_{2}$ reveals a slightly negative molecular weight dependence; $\mathrm{d} \ln A_{2} / \mathrm{d}$ $\ln M_{w}=-0.08$ for aq $\mathrm{LiOH}$ and FeTNa and -0.12 for cadoxen.

Flory's viscosity parameter $\Phi$ is defined by

$$
\Phi \equiv q_{w, z}[\eta] M_{w} /\left(6\left\langle S^{2}\right\rangle_{z}\right)^{3 / 2}
$$

where $\mathrm{q}_{w, z}$ is the polymolecularity correction factor. Here we assumed the Schulz-Zimm type distribution function with $M_{w} / M_{n}=2$. $\Phi$ values of cellulose in aq $\mathrm{LiOH}$ are collected in the eighth column of Table IV and its molecular weight dependence is shown in Figure 7 , in which the data on cellulose in cadoxen 


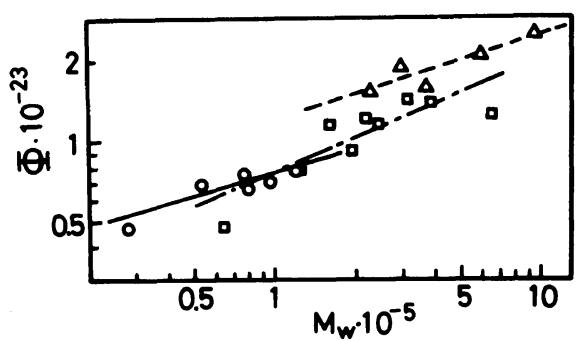

Figure 7. The molecular weight dependence of the Flory's viscosity parameter $\Phi$ of cellulose in $6 \mathrm{wt} \%$ aq LiOH (O), cadoxen $(\triangle)^{3}$ and FeTNa $(\square)^{9}$ at $25^{\circ} \mathrm{C}$.

and FeTNa are also included. Obviously, the $\Phi$ values are significantly smaller than the theoretical value at unperturbed, non-draining limit $\left(\Phi_{\mathrm{o}}(\infty)=2.87 \times 10^{23}\right){ }^{12}$

The molecular weight dependence of $\Phi$ can be expressed by

$$
\Phi=K_{\Phi} M_{w}^{a} \Phi
$$

where $K_{\Phi}$ and $a_{\Phi}$ are constants for a given cellulose-solvent combination at a given temperature. $a_{\Phi}$ for aq $\mathrm{LiOH}$ solution was 0.25 , which is compared with 0.43 and 0.30 , previously evaluated for cadoxen and FeTNa. ${ }^{11}$. As found for numerous cellulose derivative solutions, ${ }^{11}$ the partially free draining effect on the hydrodynamic properties cannot be ignored also in cellulose solutions. In a previous paper, ${ }^{6}$ we observed that specific interaction exists between cellulose acetate (CA) polymer with $\langle F\rangle$ of $0.49-2.92$ and solvent, and the degree of the partial free-drainage is larger for the systems having larger $s_{\mathrm{o}}$. The draining effect was explained by the fact that boundary between solvated polymer molecules and nonsolvated solvent becomes obscure as $s_{\mathrm{o}}$ becomes large. Analysis on the chemical shift of NMR spectrum and the adiabatic compressibility for cellulose-aq $\mathrm{LiOH}$ system indicated that the solvation exists for the system, and $s_{\mathrm{o}}$ was estimated to be 4 assuming that only $\mathrm{Li}^{+}$ solvated to cellulose. ${ }^{13}$ For cellulose-aq $\mathrm{LiOH}$ system, the draining effect may be closely correlated with the solvation.

The linear expansion factor $\alpha_{s}$, defined by

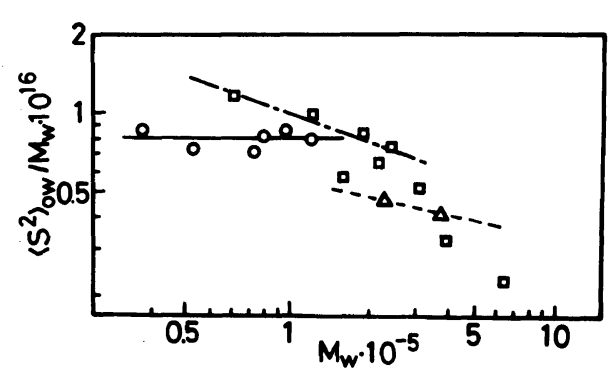

Figure 8. The ratio of the unperturbed mean-square radius of gyration $\left\langle S^{2}\right\rangle_{0, w}$ to the weight-average molecular weight $M_{w}$ as a function of $M_{w}$ of cellulose in $6 \mathrm{wt} \%$ aq LiOH $(O)$, cadoxen $(\triangle)$, and FeTNa $(\square)$ at $25^{\circ} \mathrm{C}$. Two samples with $M_{w}=3.7 \times 10^{5}$ and $9.45 \times 10^{5}$ in ref 3 gave $\psi$ values higher than the limiting value (ca. 0.198 ) of $\psi$ estimated by KFSY-I theory at infinite $\bar{z}$ and for these samples $\alpha_{\mathrm{s}}$ could not be determined.

the ratio of the weight-average radius of gyration $\left\langle S^{2}\right\rangle_{w}^{1 / 2}$ to $\left\langle S^{2}\right\rangle_{0, w}^{1 / 2}$ (the subscript. 0 means the unperturbed state), can be evaluated indirectly from the penetration function $\psi,{ }^{14}$

$$
\psi \equiv \bar{z} h_{\mathrm{o}}(\bar{z})=0.746 \times 10^{-25} A_{2} M_{w}^{2} /\left\langle S^{2}\right\rangle_{w}^{3 / 2}
$$

where

$$
\bar{z}=z / \alpha_{\mathrm{s}}^{3}
$$

$z$ is the excluded volume effect parameter. According to Kurata-Fukatsu-SotobayashiYamakawa (KFSF-I) theory, $\bar{z} h_{0}(\bar{z})$ is related to $\bar{z}$ through the relation ${ }^{15}$

$$
\bar{z} h_{\mathrm{o}}(\bar{z})=(1 / 5.047)\left\{1-(1+0.683 \bar{z})^{-7.39}\right\}
$$

and in the small $\alpha_{\mathrm{s}}$ region, we can employ the relation, ${ }^{16}$

$$
\alpha_{\mathrm{s}}^{3}-1=1.78 z
$$

Putting the experimental data on $A_{2}, M_{w}$, and $\left\langle S^{2}\right\rangle_{w}^{1 / 2}$ into eq $7-10, \alpha_{s}$ was evaluated and tabulated in the ninth column of Table IV. Here, $\left\langle S^{2}\right\rangle_{w}^{1 / 2}$ is converted from $\left\langle S^{2}\right\rangle_{z}^{1 / 2}$ assuming the Schulz-Zimm distribution with $M_{w} / M_{n}=2 . \alpha_{\mathrm{s}}$ reveals the molecular weight dependence (i.e., $\quad \mathrm{d} \ln a_{\mathrm{s}} / \mathrm{d} \ln M_{w} \quad\left(\equiv a_{1} / 3\right)=$ 0.018 , accordingly, $a_{1} \cong 0.054$ ) and lies below 1.04 for $M_{w} \leq 1.2 \times 10^{5}$.

Figure 8 shows the ratio of $\left\langle S^{2}\right\rangle_{o, w} / M_{w}$ as a function of $M_{w}$ for cellulose in aq $\mathrm{LiOH}$ 
solution. Here $\left\langle S^{2}\right\rangle_{0, w}$ was calculated from $\left\langle S^{2}\right\rangle_{w}$ with $\alpha_{\mathrm{s}}$. The figure includes the values of $\left\langle S^{2}\right\rangle_{0, w} / M_{w}$ calculated from the literature data for cellulose in cadoxen and FeTNa. $\left\langle S^{2}\right\rangle_{0, w} / M_{w}$ is almost constant $\left(\sim 8 \times 10^{-17}\right.$ $\mathrm{cm}^{2}$ ) over wide $M_{w}$ range for cellulose in aq LiOH solution. The values of $\left\langle S^{2}\right\rangle_{0, w} / M_{w}$ in cadoxen and FeTNa decrease with increasing $M_{w}$. In the metal complex alkali solvents, nonGaussian nature of cellulose chain may have a close correlation with formation of cellulose-metal complex. ${ }^{17}$ An increase in rigidity of the unperturbed chain with decrease in $M_{w}$ suggests that the effect of the metal complex formed at the unreducing end of cellulose chain becomes remarkable in lower $M_{w}$ region. In contrast to this, cellulose in aq alkaline solution can be regarded as Gaussian at its unperturbed state.

A of cellulose in aq $\mathrm{LiOH}$ was evaluated using the following six methods.

\section{Method 2B}

$$
A=\left(6\left\langle S^{2}\right\rangle_{w} / \alpha_{\mathrm{s}}^{2} M_{w}\right)^{1 / 2}
$$

Method 2C: Baumann ${ }^{18}$

$$
\left\langle S^{2}\right\rangle_{w}^{3 / 2} / M_{w}^{3 / 2}=A^{3} / 6^{3 / 2}+\left(1 / 4 \pi^{3 / 2}\right) B M_{w}^{1 / 2}
$$

where $B$ is the long-range interaction parameter.

Method 2E: Stockmayer-Fixman ${ }^{19}$

$$
\begin{aligned}
{[\eta] / M_{w}^{1 / 2}=} & \Phi_{0}(\infty) A^{3} \\
& +2(3 / 2 \pi)^{3 / 2} \Phi_{0}(\infty) B M_{w}^{1 / 2}
\end{aligned}
$$

Method 2F: Kamide-Moore ${ }^{20}$

$$
\begin{aligned}
& -\log K_{\mathrm{m}}-\log \{2(1-a)\} \\
& \quad=-\log \left(\Phi_{0}(\infty) A^{3}\right)+(a-0.5) \log M_{0}
\end{aligned}
$$

$M_{0}$ is a parameter depending on the molecular weight rage, $M_{1}-M_{2}$ to which eq 2 can be applied and the geometric mean $\left(M_{1} M_{2}\right)^{1 / 2}$ can be regarded as a good approximation to $M_{0}$.

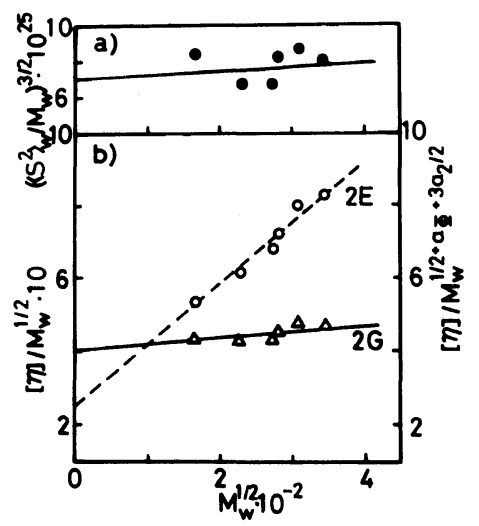

Figure 9. Plots of $\left(\left\langle S^{2}\right\rangle_{w} / M_{w}\right)^{3 / 2}$ (Method 2C) (a), [ $\left.\eta\right] /$ $M_{w}^{1 / 2}$ (Method 2E) (b), and $[\eta] / M_{w}^{1 / 2}+a_{\Phi}+3 a_{2} / 2$ (Method 2G) (b) versus $M_{w}^{1 / 2}$ of cellulose in $6 \mathrm{wt} \%$ aq

\begin{tabular}{|c|c|c|c|c|}
\hline \multirow{2}{*}{ Method } & \multirow{2}{*}{$\frac{A \times 10^{8}}{\mathrm{~cm}}$} & \multirow{2}{*}{$\frac{B \times 10^{27}}{\mathrm{~cm}^{3}}$} & \multirow{2}{*}{$\sigma^{\mathrm{a}}$} & \multirow{2}{*}{$C_{\infty}$} \\
\hline & & & & \\
\hline $2 \mathrm{~B}\left(\alpha_{\mathrm{s}}\right.$ from $\left.\Psi\right)$ & 2.19 & - & $3.5_{7}$ & $30_{6}$ \\
\hline $2 \mathrm{C}\left(a_{2}=0\right)$ & 2.18 & 4.5 & $3.5_{5}$ & $30 \cdot 3$ \\
\hline $2 \mathrm{E}\left(a_{2}=a_{\Phi}=0\right)$ & 0.95 & 1.6 & $1.5_{5}$ & $5.7_{5}$ \\
\hline $2 \mathrm{~F}\left(a_{2}=a_{\Phi}=0\right)$ & 1.02 & - & $1.6_{6}$ & $6.6_{3}$ \\
\hline $2 \mathrm{G}\left(a_{2} \neq 0, a_{\Phi} \neq 0\right)$ & 2.13 & 6.4 & $3.4_{7}$ & 28.9 \\
\hline $2 \mathrm{~K}\left(a_{2} \neq 0, a_{\Phi} \neq 0\right)$ & 2.13 & - & $3.4_{5}$ & 28.9 \\
\hline Most probable ${ }^{b}$ & 2.16 & & $3.5_{2}$ & 29.7 \\
\hline
\end{tabular}
$\mathrm{LiOH}$ at $25^{\circ} \mathrm{C}$. $\mathrm{O}$, Method 2E; $\triangle$, Method $2 \mathrm{G}$.

Table VI. Unperturbed chain dimension $A$, long-range interaction parameter $B$, conformation parameter $\sigma$, and characteristic ratio $C_{\infty}$ of cellulose in aq $\mathrm{LiOH}$ at $25^{\circ} \mathrm{C}$

Method 2G: Kamide-Miyazaki (I) ${ }^{11}$

$$
\begin{aligned}
& {[\eta] / M_{w}^{1 / 2+a_{\Phi}+3 / 2 a_{2}}} \\
& \quad=6^{3 / 2} K_{\Phi} K_{0}^{3 / 2}+0.66 K_{\Phi} B M_{w}^{\left(1-3 a_{2}\right) / 2}
\end{aligned}
$$

with

$$
a_{2}=\mathrm{d} \ln \left(\left\langle S^{2}\right\rangle_{0, w} / M_{w}\right) / \mathrm{d} \ln M_{w}
$$

and

$$
K_{0}=\left(A^{2} / 6\right) M_{w}^{a_{2}}
$$


Table VII. Unperturbed chain dimension $A$ and conformation parameter and characteristic ratio $C_{\infty}$ of cellulose in aq $\mathrm{LiOH}$, cadoxen and iron-sodium-tartrate $(\mathrm{FeTNa})$ at $25^{\circ} \mathrm{C}$

\begin{tabular}{|c|c|c|c|c|c|c|c|c|}
\hline \multirow{3}{*}{ Solvent } & \multicolumn{6}{|c|}{$A \times 10^{8} / \mathrm{cm}$} & \multirow{3}{*}{$\sigma$} & \multirow{3}{*}{$C_{\infty}$} \\
\hline & \multicolumn{3}{|c|}{ Thermodynamic approach } & \multicolumn{2}{|c|}{ Hydrodynamic approach } & \multirow{2}{*}{$\begin{array}{c}\text { Most } \\
\text { probable }\end{array}$} & & \\
\hline & $2 B$ & $2 \mathrm{C}$ & $2 D^{a}$ & $2 \mathrm{G}$ & $2 \mathrm{~K}$ & & & \\
\hline $\mathrm{Aq} \mathrm{LiOH}$ & 2.19 & 2.18 & - & 2.13 & 2.13 & 2.16 & $3.5_{2}$ & 29.7 \\
\hline Cadoxen & $1.80^{\mathrm{b}}$ & - & $1.92^{\mathrm{a}, \mathrm{b}}$ & $1.57^{\mathrm{a}, \mathrm{b}}$ & $1.56^{\mathrm{b}, \mathrm{c}}$ & 1.71 & $2.7_{9}$ & 18.6 \\
\hline $\mathrm{FeTNa}$ & $2.45^{\mathrm{b}}$ & - & $2.27^{\mathrm{a}, \mathrm{b}}$ & $2.17^{\mathrm{a}, \mathrm{b}}$ & $2.07^{b, c}$ & 2.24 & $3.6_{5}$ & 32.0 \\
\hline
\end{tabular}

a Reference 11.

b Value at $M_{w}=1 \times 10^{5}$.

c Reference 21 .

Method 2K: Kamide-Saito (I) ${ }^{21}$

$$
\begin{aligned}
& -\log K_{\mathrm{m}}+\log \left\{2\left(1-a+a_{\Phi}\right)\right\} \\
& +1.5 \log 6+\log K_{\Phi}=1.5 \log K_{0} \\
& +\left(a-0.5-a_{\Phi}\right) \log M_{0}
\end{aligned}
$$

Figure 9 shows the plots according to method $2 \mathrm{C}, 2 \mathrm{E}$ and $2 \mathrm{G}$ for cellulose aq $\mathrm{LiOH}$ system at $25^{\circ} \mathrm{C}$, in which $a_{2}$ was taken to be zero. From the intercept and the slope of the plots $A$ and $B$ are determined. The $A$ values obtained are summarized in Table VI. The conformation parameter $\sigma$ and characteristic ratio $C_{\infty}$. are defined by eq 19 and 20 , respectively.

$$
\sigma=A / A_{\mathrm{f}}
$$

and

$$
C_{\infty}=A_{\infty}^{2} M_{\mathrm{b}} / l^{2}
$$

where $A_{\mathrm{f}}$ is the $A$ value of the hypothetical chain with free rotation $\left(=0.614 \times 10^{-8} \mathrm{~cm}\right.$ for cellulose), $A_{\infty}$ the asymptotic value of $A$ at infinite molecular weight (in the case of $a_{2}=0$, $A$ value at $M_{w}=1 \times 10^{5}$ is utilized as $\left.A_{\infty}\right), M_{\mathrm{b}}$ the molecular weight per skeletal bond, and $l$ the mean bond length. $\sigma$ and $C_{\infty}$ are compiled in Table VI. Method 2E and 2F assume $a_{2}=0$ and $a_{\Phi}=0$ as described before ${ }^{11}$ and the latter assumption is unacceptable for cellulose-aq LiOH solution. Thus, these methods signifi- cantly underestimate $A$. The most probable $A$ values are considered those from $2 \mathrm{~B}, 2 \mathrm{C}, 2 \mathrm{G}$, and $2 \mathrm{~K}$. The $B$ value scatters depending on the procedures employed. B by method $2 \mathrm{G}$ was $4.5 \times 10^{-27} \mathrm{~cm}^{3}$ and comparable with $3.7 \times 10^{-27} \mathrm{~cm}^{3}$ for $\mathrm{CA}$ with $\langle F\rangle=2.92$ in DMAc.

Table VII shows $A$ values estimated by the methods applicable to non-Gaussian, partially draining chains for cellulose in aq $\mathrm{LiOH}$, cadoxen and FeTNa. The average $A$ value $\left(A_{\mathrm{m}}\right)$ of cellulose in aq $\mathrm{LiOH}$ is close to that of FeTNa. The $\sigma$ values in three solvents range from 2.8 to 3.7 , suggesting that cellulose dissolves as semiflexible chains. In the pre-

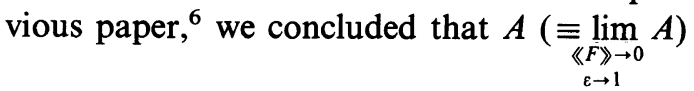
of CA in the hypothetical non-polar solvent coincides with $A_{\mathrm{f}}$ and cellulose behaves as a freely rotating chain. Since three solvents employed in this study are highly polar, discrepancy of the $A$ value from $A_{\mathrm{f}}$ may be explained by the steric hindrance due to the solvation.

The exponent $a$ in MHS equation (eq 2) can be divided into four parts ${ }^{11}$ :

$$
a=0.5+a_{\Phi}+a_{1}+1.5 a_{2}
$$

For cellulose-aq LiOH system, $a_{\Phi}=0.25, a_{1}=$ 0.05 and $a_{2}=0$ were obtained. Then from eq 
$21 a=0.80$ is expected. This is in good agreement with the experimental $a(=0.79)$. The most important factor contributing to the magnitude of $a$ is evidently $a_{\Phi}$, and the excluded volume effect is very small.

Analyzing the literature data on solution properties of 19 pairs among cellulose, its derivatives, and solvents, Kamide and Miyazaki ${ }^{11}$ concluded that (1) the partially free draining effect on hydrodynamic properties exists $\left(a_{\Phi}>0\right)$, (2) the special distribution of segments is often non-Gaussian $\left(a_{2} \leq 0\right)$, (3) the fact of $a_{\Phi}>0$ and $a_{2}<0$ indicates the inapplicability of methods $2 \mathrm{E}$ and 2F for estimating $A$, (4) cellulose and its derivatives are not flexible, but semi- or inflexible polymers and (5) the expansion factor $\alpha_{\mathrm{s}}$ is usually close to unity and the excluded volume effect is small. The characteristic features of the solution properties of cellulose in aq $\mathrm{LiOH}$ can be well described by the above conclusions except (2).

In summary, cellulose dissolves molecularly in aq $\mathrm{LiOH}$ solution and behaves as Gaussian chain in the solvent at unperturbed state. The excluded volume effect is small, but the draining effect can never be ignored.

\section{REFERENCES}

1. M. Terbojevich, A. Cosani, G. Conio, A. Ciferi, and E. Bianchi, Macromolecules, 18, 640 (1985).

2. K. Kamide, K. Okajima, T. Matsui, and K. Kowsaka, Polym. J., 16, 857 (1984).
3. D. Henley, Ark. Kemi, 18, 327 (1961).

4. W. Brown and R. Wirkström, Eur. Polym. J., 1, 1 (1965).

5. H. Suzuki, Y. Miyazaki, and K. Kamide, Eur. Polym. J., 16, 703 (1980) and the references cited therein.

6. K. Kamide and M. Saito, Eur. Polym. J., 20, 903 (1984).

7. H. Vink and G. Dahlström, Makromol. Chem., 109, 249 (1967).

8. C. Strazielle, "Light Scattering from Polymer Solutions," M. B. Huglin, Ed., Academic Press, New York, N. Y., 1972, Chapter 15, p 652.

9. L. Valtassari, Makromol. Chem., 150, 117 (1971).

10. G. Jayme and W. Verburg, Rayon, Zellwolle, Chemifasern, 32, 193, 275 (1954).

11. K. Kamide and Y. Miyazaki, Polym. J., 10, 409 (1978).

12. See, for example, H. Yamakawa, "Modern Theory of Polymer Solutions," Harper \& Row, New York, N. Y., 1971, Chapter 31, p 270.

13. K. Kamide and $M$. Saito, to be published in elsewhere.

14. See, for example, M. Kurata, "Industrial Chemistry of High Polymers," Vol. III, Modern Industrial Chemistry No. 18, Asakura, Tokyo, 1975, Chapter 4.

15. M. Kurata, M. Fukatsu, H. Sotobayashi, and H. Yamakawa, J. Chem. Phys., 41, 139 (1964).

16. M. Fixman, J. Chem. Phys., 36, 3123 (1962).

17. E. Ott ed., "Cellulose and Cellulose Derivatives," High Polymers, Vol. V, Interscience Publishers, New York, N. Y., 1943, Chapter VIII, p 750.

18. H. Baumann, J. Polym. Sci., Polym. Lett., 3, 1069 (1965).

19. W. H. Stockmayer and M. Fixman, J. Polym. Sci., C, 1, 137 (1963).

20. K. Kamide and W. R. Moore, J. Polym. Sci., B, 2, 1029 (1964).

21. K. Kamide and M. Saito, Eur. Polym. J., 17, 1049 (1981). 